\title{
Trainee Counselor Development of Social Justice Counseling Competencies
}

\author{
Thomas A. Field \\ Boston University School of Medicine \\ Michelle R. Ghoston \\ Wake Forest University \\ Tameka O. Grimes \\ Virginia Tech \\ Debbie C. Sturm \\ James Madison University \\ Manjot Kaur \\ City University of Seattle \\ Annisa Aninditya \\ City University of Seattle \\ Marcus Toomey \\ City University of Seattle
}

\begin{abstract}
This grounded theory study sought to identify the process by which master's level counselors-in-training (CITs) develop social justice counseling competencies. Participants $(N=41)$ from a clinical mental health counseling (CMHC) program were interviewed at pre-practicum, pre-internship, and post-internship phases. CITs progressed through the stages of exposure, recognition, and action, influenced by self-reflection and attitudes. These stages differed from the awareness, knowledge, and skills domains identified in prior multicultural and social justice counseling literature. Most CITs planned advocacy action steps by the conclusion of their program, though few implemented them. Implications for counselor educators are discussed.
\end{abstract}

Keywords: social justice; MSJCC; trainee; counselor development; competency. 


\section{Trainee Counselor Development of Social Justice Counseling Competencies}

The recently integrated multicultural and social justice counseling competencies (MSJCCs; Ratts, Singh, Nassar-MacMillan, Butler, \& McCullough, 2016) reflect the "seamless connection" (Ratts, 2011, p. 24) between multicultural competencies and working with clients in combination with advocacy actions needed to remedy systemic injustices. In 2016, Ratts et al. revised the original multicultural counseling competencies by Sue, Arredondo, and McDavis (1992) to add a fourth competency for counselors to take action and advocate. This fourth competency area was in addition to developing awareness of attitudes and beliefs, knowledge, and skills (AKS) relevant to multicultural counseling (Sue et al.,, 1992; Sue \& Sue, 2013) and social justice counseling (Ratts et al., 2016). The revised MSJCCs, therefore, outlined four types of aspirational competencies: attitudes and beliefs, knowledge, skills, and action (AKSA; Ratts et al., 2016). This addition reflected the new integration of multicultural and social justice counseling competence.

The MSJCCs are important guidelines for all counselors to consider when working with clients. Yet to date, sparse guidance is available regarding how to implement the new MSJCCs in graduate programs that train counseling students. While a significant body of information exists for when and how students master multicultural counseling competencies (e.g., Collins, Arthur, Brown, \& Kennedy, 2015; Hipolito-Delgado, Cook, Avrus, \& Bonham, 2011; Prosek \& Michel, 2016), no studies currently exist that examine the impact of social justice training on students' development of social justice and advocacy counseling competencies. Existing literature tends to provide guidance about developing an academic climate that emphasizes social justice training by modifying the core mission, objectives, and course content of the program (e.g., Bemak, Chung, Talleyrand, Jones, \& Daquin, 2011). The majority of articles exploring social justice training during clinical practica and internships address doctoral-level training in psychology (e.g., Collins, Arthur, Brown, \& Kennedy, 2015; Lewis, 2010). For example, Lewis (2010) examined the process by which doctoral students in psychology practiced different forms of social justice at their site. Lewis (2010) identified three forms of social justice in the literature, namely interactional justice, procedural justice, and distributive justice (e.g., Colquitt \& Greenberg, 2003). Lewis (2010) described interactional justice as the trainee's display of respect and dignity to clients, whereas both procedural and distributive justice required the trainee to advocate on behalf of their clients. Procedural justice was defined as the trainee advocating for the just distribution of goods and services, such as access to health care and educational services. For distributive justice, the trainee advocated for fair processes by which these distributions were allocated (i.e., funding). Lewis (2010) found in his study that doctoral students demonstrated interactional justice initially during their practicum sequence. Students then demonstrated procedural and distributive justice towards the conclusion of their practicum sequence, gaining skills relevant to the legislative process, public policy, lobbying, and advocacy.

\section{Purpose of this Study}

The current authors sought to address the gap in the literature regarding how counseling students develop social justice counseling competencies during their graduate program, and what training approaches seem to be beneficial. The purpose of this study was to examine how counselors-in-training (CITs) who are enrolled in a master's-level clinical mental health counseling (CMHC) program develop strong social justice and advocacy counseling competencies during practicum and internship. Multicultural competence was not directly measured in this study, as the purpose was to address the research gap regarding how CITs develop social justice counseling competencies specifically. The research question guiding this study was, how, when, why, and to what extent do CMHC trainees develop social justice and advocacy counseling competencies during their master's-level practicum and internship experiences?

\section{Methodology}

The authors chose a qualitative grounded theory methodology to address the research questions. They sought to understand the unique perspectives of participants (Corbin \& Strauss, 2014), and then identify an 
inductive developmental model for social justice counseling competence that emerged from the data (Charmaz, 2014). The authors used the constant comparative method from grounded theory (Corbin \& Strauss, 2014) to create categories that represented developmental stages. The constant comparative method is used to develop concepts from data by coding and analyzing at the same time (Corbin \& Strauss, 2014). When using the constant comparative method, the researcher sorts and classifies new codes into existing categories or creates new categories to capture data that do not fit existing categories.

The authors approached the data from a traditional grounded theory position (Corbin \& Strauss, 2014) rather than a constructivist grounded theory approach (Charmaz, 2014; Mills, Bonner, \& Francis, 2006). Consistent with traditional grounded theory (Corbin \& Strauss, 2014), the authors attempted to bracket researcher assumptions and bias, used consensus during coding and analysis, and endeavored to ensure the coding, analysis, and findings were accurate to participant descriptions. The research team reviewed and discussed the emerging model to ensure that the theory was grounded in data and accurately reflected participant experiences. The authors hoped that findings would be transferable to other counselor education programs. While the authors believed that participants' reality was socially co-constructed (Lincoln \& Guba, 2013) and attributed importance to all responses regardless of frequency, the authors did not take an interpretive approach to coding and analysis nor seek to co-construct meaning between the multiple researchers and participants. In this regard, the authors were oriented toward a more post-positivistic epistemology reflected in more traditional grounded theory than in constructivist grounded theory (Mills et al., 2006).

\section{Participants}

The authors recruited CITs from a CMHC master's program in the Northwestern United States that was accredited by the Council for the Accreditation of Counseling and Related Educational Programs (CACREP). All CITs were currently enrolled CMHC students at the time of the study. All participants who met eligibility criteria (i.e., all those who were in the program) were invited into the study and asked to answer demographic questions for the purpose of describing the resulting participant sample and for context in interpreting the data. While the authors collected demographic information from participants to describe the sample, it was not used to screen interviewees for inclusion into the study. The authors felt that such screening based on demographics would have been inappropriate, because all CITs attended the same university where the research was conducted. Thus, the authors used convenience sampling to recruit participants.

Participants $(N=41)$ self-reported their cultural identities. Regarding gender, participants identified as female $(73.2 \%, n=30)$, male $(24.4 \%, n=10)$, and non-binary $(2.4 \%, n=1)$. No students self-identified as transgender. A sizeable minority of students $(24.4 \%, n=10)$ identified as having a lesbian, gay, or bisexual sexual/affective orientation. Participants reported their race/ethnicity as Euro-American/Caucasian $(68.3 \%, n=$ 28), Asian/Asian-American (14.6\%, $n=6)$, African/African-American (4.9\%, $n=2)$, Hispanic/Latinx $(4.9 \%, n$ $=2)$, Native American $(4.9 \%, n=2)$, and Multiracial $(2.4 \%, n=1)$. No participants identified as Native Alaskan, Native Hawaiian, nor Pacific Islander. Participants' age ranged from 22 to 56 years, with an average of 31.8 years $(S D=8.6$ years $)$ and median of 29 years. Participants varied in the amount of pre-experience in the mental health field they had obtained prior to entering graduate school. Nearly two-thirds of participants $(63.4 \%, n=$ 26) had zero pre-experience. Of the remaining 15 participants, 13 participants had two to three years of preexperience. The remaining two participants had a much greater amount of experience, at ten and fifteen years. Thus, while the median number of pre-experience years was zero, the average was 1.3 years with a large standard deviation $(S D=2.8$ years $)$.

All CMHC trainees who were about to enter the practicum phase of training were invited to participate in the study. To enroll in practicum, students in the program had to complete a year of academic coursework that included most of the CACREP core courses (e.g., professional orientation and ethical practice, social and cultural foundations, etc.). Two years of cohorts were invited to participate. Across the cohorts, $41 \mathrm{CMHC}$ trainees participated from a pool of $47 \mathrm{CMHC}$ students (87.2\% response rate). Demographics for the six 
trainees who elected not to participate in the study (70\% female, $n=4 ; 30 \%$ male, $n=2 ; 83.3 \%$ Euro-American/ Caucasian, $n=5 ; M$ age $=31.67$ years) were roughly equivalent to those who participated. The authors sought to protect participant privacy to the extent possible by scheduling interviews during times when participants were not expected to be on campus (e.g., classes), to blind cohort members from knowing which of their peers were study participants.

\section{Procedure}

Participants were recruited to participate in the study through online and in-class announcements that followed the recruitment script approved by the first author's IRB. Participants received an informed consent statement, indicating the length of the study, the requirements for participation, and the ability to leave the study at any time. CITs were not given any incentive to participate in the study. Participants were informed that the study sought to understand their self-perceptions of social justice counseling competency. The authors did not inform participants of their intent to evaluate their social justice counseling competence across developmental intervals, to limit potential social desirability bias in participant responses. In the informed consent document, CITs were informed that data would not be analyzed until after their graduation from the program to mitigate pressure to persist in the study.

The authors collected data during three intervals: pre-practicum, post-practicum (pre-internship), and post-internship. The authors collected pre-practicum data during the week prior to the students' first week at their practicum site, approximately one year into their counseling program. The authors collected postpracticum (pre-internship) data approximately six months later, at the conclusion of their practicum and prior to starting their internship experience. The authors collected post-internship data during the last week of the student's internship, approximately nine months following the post-practicum measure and at the end of the counseling program. At each interval, student participants completed a demographic questionnaire and standardized structured qualitative interview. The research team used Patton's (2014) guidelines to develop interview questions addressing participant perceptions of their current social justice awareness and beliefs, knowledge, skills, and actions (Ratts et al., 2016), and their impact on counselor development. Patton (2014) recommended that interview questions should address a range of experiences, identifying six major areas: behaviors, opinions and values, feelings, knowledge, sensory, and background/demographics. Patton (2014) also recommended that questions be open-ended, be as neutral as possible, and that interviewers asked only one question at a time and avoided "why" questions. The research team created questions that adhered to these categories and recommendations.

The interview protocol was piloted with trainees who were not enrolled in the study to ensure that the interview questions adequately addressed the research questions. The authors hoped this pilot would improve data trustworthiness and validity. The authors found that the interview questions adequately collected data to answer the research questions. One question about professional identity was added to better capture more general/global CIT development outside of the three areas of social justice awareness and beliefs, knowledge, skills, and actions.

Each interview lasted for approximately 30 minutes. The same interview questions were used for prepracticum, post-practicum, and post-internship. The interview questions are included in Appendix A.

The first author trained four alumni from the program who had graduated several years before the study commenced to conduct the interviews. The interviewer, therefore, was unknown to the participants in the study. The same four alumni conducted interviews with the same participants for each of the three interviews over the 24-month data collection period to enhance consistency. The first author randomly assigned interviewers to participant interviewees. One exception to this consistency between interviewer-participant pairing occurred midway through the study. One of the interviewers left the project for several months due to medical complications. The participants assigned to this interviewer were re-allocated to another interviewer during one of the data collection periods (i.e., post-practicum). The original interviewer conducted the final 
interview for these participants (i.e., post-internship) upon returning from medical leave. All interviews were conducted individually, rather than in groups. The interviewers disclosed to participants that their identity would be masked from faculty to prevent social desirability response bias to the extent possible. Interviews were audio recorded and uploaded to a secure encrypted online data management software system.

Transcription and member checks. After 24 months of data collection concluded, an additional 12-month period elapsed before the interviews were transcribed by trained graduate students. All participants had graduated from the program at the time of transcription, thereby limiting the transcribers' connection and exposure to the study participants. Audio files were transcribed verbatim. The first author checked transcripts to ensure accuracy, before sending transcripts to participants who performed member checks to ensure consistency with their perceptions. Participants found no errors to be corrected.

Coding and analysis. A consensus coding team comprised of the first four authors coded transcripts utilizing manual line-by-line open coding. The focus on coding was to identify current experiences within and between participants in order to detect a common developmental process. Audio files were identified by an alphanumeric number corresponding to the participant identifier and the data collection interval (i.e., prepracticum, pre-internship, post-internship).

The coding team met weekly over a period of several months. The four coding team members were full-time faculty members in different counselor education programs with prior qualitative coding training and experience. The demographic representation of the coding team members was as follows. The first author identified as a cisgender heterosexual Caucasian male. The second author identified as a cisgender heterosexual African-American female. The third author identified as a cisgender heterosexual African-American female. The fourth author identified as a cisgender heterosexual Caucasian female.

The last three authors were graduate students who were trained in qualitative coding by the first author and assisted with coding transcripts during in-person coding sessions with the first author. Each graduate student author read a chapter on qualitative coding by Charmaz (2014). Graduate students only coded transcripts under the first author's in-person supervision, and did not code transcripts independently. The demographics of these graduate student authors were as follows. The fifth author identified as a cisgender heterosexual Asian-American female. The sixth author identified as a cisgender heterosexual Asian female. The seventh author identified as a cisgender bisexual Caucasian male.

The team independently coded the first four transcripts (with the trained graduate students coding the transcript with the first author), and discussed coding discrepancies during meetings. The first four transcripts were intentionally selected, with two transcripts selected for the same two participants (i.e., pre-practicum and post-practicum) to ensure the team was developing codes relevant to data collection intervals across participants. These two participants were at the extreme ends of the range for the amount of pre-existing experiences in the mental health field prior to entering the counselor education program (i.e., 0 and 15 years) to seek the greatest amount of variation during initial coding to prevent early redundancy (Charmaz, 2014).

The coding team developed a codebook from the first four coding meetings, comprised of emergent codes. Following the first set of transcripts, the first four authors coded transcripts independently. Inconsistencies in coding were resolved by the coding team using consensus to clarify the final coding for that transcript section. No unresolvable disagreements occurred among the team members during the coding process. The research team organized emergent codes through axial coding. Codes were inputted into NVivo 11 (QSR International, 2010) for organization and comparison by demographic variables and by phases of development. The team stopped coding transcripts after completing coding for 37 participants across all three time intervals (i.e., prepracticum, post-practicum, post-internship), as saturation and redundancy had been reached.

\section{Training Program}

Prior to enrollment in practicum, all CMHC trainees completed coursework in multicultural and social justice counseling through both a formal didactic course (Multicultural Counseling) and instruction/ 
reflection integrated into each of the CACREP common core coursework about cultural diversity and social justice concepts. For example, during the ethics course, students identified advocacy action steps for addressing a social justice concern in a client case vignette. During their practicum and internship, all 48 CMHC trainees (including the 41 participants in the study) engaged in exercises and assignments during university-based group supervision that attempted to help them demonstrate MSJCCs. These exercises and assignments included (1) discussion prompts about social justice issues that trainees were observing at their site, (2) assigned readings and in-class discussion from the text, Beyond the 50-Minute Hour: Therapists Involved in Meaningful Social Action (Kottler, Englar-Carlson, \& Carlson, 2013), (3) case presentations that addressed social justice issues and potential areas for advocacy, and (4) biweekly journal prompts that addressed social justice issues that trainees were observing at their site. These exercises and assignments were part of the CMHC practicum and internship curriculum and were not developed specifically for this research project. Thus, all CITs completed these exercises and assignments regardless of participation in the study.

\section{Trustworthiness}

The authors attempted to enhance the trustworthiness of this study by following several procedures identified in the literature (Merriam \& Tisdell, 2015). First, we considered the positioning of the research team to reduce the potential for bias. The research team consisted of persons with emic and etic exposure to the counselor education program to balance the perspective of the first author who worked in the setting where the study took place. The second, third, and fourth authors all worked at separate counselor education programs. The trained graduate students (fifth, sixth, seventh authors) had no connection to the participants in the study. The first author was the sole person with any connection to the participants in the study. To protect against the first author's coder bias, all transcripts were given alphanumeric codes and the document that connected codes to participants was developed by another research team member. The first author also coded transcripts with trained graduate students and other research team members to reduce bias.

The authors identified prior assumptions and biases prior to commencing coding and throughout the coding process. The research team discussed their own bias towards the importance of social justice training and an identity as a social justice advocate. Faculty authors discussed their own program's approach to social justice training, and students discussed their own experience. The authors bracketed biases that included the belief that cultural variables would predict social justice counseling competence. For example, the authors discussed and bracketed their pre-existing belief that White identity would prevent or limit CIT development of social justice counseling competence, because of White identity's association with ethnocentrism and unconscious privilege (Sue \& Sue, 2013). During coding meetings, the team leaned towards in vivo coding rather than theoretical coding, to reduce the possibility of bias (Corbin \& Strauss, 2014). Member checks were established by emailing initial transcripts and analyses to participants to ensure consistency with their perceptions and experience. The authors maintained an audit trail throughout the process.

\section{Results}

All participants $(N=41)$ completed the study, with no early drop-outs. This exceeded the sample size requirement for grounded theory research used by most qualitative authorities (e.g., Charmaz, 2014; Creswell \& Poth, 2017). For example, Creswell and Poth (2017) suggested 20-30 interviewees for grounded theory studies. Through emergent consensus coding and the constant comparative method of grounded theory research, the research team identified thematic categories for developmental stages by which CITs in the study developed social justice counseling competencies. The research team also identified thematic categories for the phase of training. The three developmental stages were exposure, recognition, and action. These categories were related to but different from the aspirational domains of awareness, knowledge, and skills identified by Ratts et al. (2016) and Sue et al. (1992). Even though interviews were conducted at the pre-practicum, post-practicum, and post-internship intervals, qualitative data reflected three different phases of training: pre-program, pre- 
practicum, and supervised field experience. The narrative below describes the three developmental stages, with analyses organized by training phase (i.e., pre-program, pre-practicum, supervised field experience) for each developmental stage.

\section{Stage 1: Exposure}

Exposure pertained to personal experiencing or direct observation of social injustice or inequity. Throughout the training experience, exposure to social justice and advocacy issues was ongoing and recursive. For example, new exposure to social injustice and inequity occurred when CITs took action by supporting clients and advocating on their behalf.

Pre-program. CITs differed in their first exposure to social justice experiences. Some CITs reported exposure during childhood, whereas others reported being raised in privileged environments and did not experience personal exposure to social justice issues until undergraduate or graduate study. One pre-practicum CIT stated,

In my past, I don't feel that I was aware of any social justice or advocacy issues. I'm just so removed. If you don't notice what is going on around you, you're unaware. And you just kinda ignore, even though you know it's there, it just fades into the background. So being in the counseling program has made me more attentive to social justice issues. (Participant B)

Personal experiences of exposure to social justice issues during childhood were fairly diverse. CITs experienced and/or observed discrimination, prejudice, marginalization, and oppression through experiencing racism, sexism, and homophobia; living with a parent who had a significant mental disorder and encountering community stigma; low SES households; homelessness; parental incarceration; lacking systemic social supports; awareness of resources yet inability to access them; and powerlessness to self-advocate as a child. For some CITs, exposure to social justice issues occurred through discussions with parents and their experiences in religious traditions. During adulthood, a few CITs experienced barriers to education and employment prior to entering the counseling program.

As they progressed through their first year of their studies, CITs reflected on their pre-existing awareness of multicultural and social justice issues before they joined the program. CITs differed in their degree of awareness. Some CITs had high levels of multicultural and social justice awareness, and self-reported a desire for more social justice training. As one pre-practicum CIT reported,

Social justice is something that I have been interested in for some time, and probably will become my specialty in counseling. I came in with a lot of information. I feel like I am biased, because I came in wanting social justice training. (Participant J)

In contrast, some CITs reflected during interviews that they had little to no awareness of multicultural and social justice issues prior to entering the counseling program. CITs who lacked pre-program awareness of multicultural and social justice issues specifically mentioned being unaware of their White racial identity and White privilege. These CITs became more knowledgeable about social justice issues when exploring their White identity and privilege pre-practicum. Personal experiences with racial identity formation helped White CITs to observe social injustice and inequality. As one pre-practicum CIT shared,

I've become more aware. Sometimes it is hard to look at my privilege and know that I do have a lot of resources. And look at other people and say, how did you not get all the resources? You know, is it White privilege, is it that I just got lucky? (Participant M)

Pre-practicum. The vast majority of CITs identified exposure to social justice themes throughout the CMHC curriculum related to racism, homophobia, discrimination, oppression, poverty, and issues related to gender and sexual identity. CITs reported exposure through discussions in class, conversations with faculty outside of class, reading case studies, and through their multicultural counseling course. Some students believed 
that multiple avenues of exposure were important, because mere textbook readings were not sufficient for developing awareness and knowledge of social justice issues. A few students seemed to demonstrate higher levels of critical thinking regarding curricula decisions. For example, one pre-practicum CIT mentioned that:

One thing I notice is, about $80 \%$ of our books are written by White men. You're not going to be always talking about social justice in every class, but where is the advocacy if you're not teaching from a diverse perspective, if that makes sense. Um... and I think [the counselor education program] is trying, I mean I don't see it being resistant or anything. But I think it's possible to subvert that a little bit more. (Participant E)

Supervised field experiences. All CITs experienced exposure to social justice issues throughout their supervised field experiences. Students reported significant exposure to a multitude of social justice issues facing clients during practicum and internship experiences. For example, CITs observed client experiences with struggling to navigate systemic social supports, facing educational barriers, homelessness, homophobia, inability to access counseling services because of difficulties with attaining affordable child care, incarceration, poverty and low-income, racism, problems with the foster care system, unemployment and difficulties finding work, White privilege, and the "uneven playing field." On multiple occasions, CITs called such experiences "eye opening" and felt that this exposure enhanced their own recognition of social injustice. As one post-internship CIT shared, "The social justice issues that I've seen in my work with clients... the homelessness, discrimination, racial prejudice, have been a big eye opener for me" (Participant K).

\section{Stage 2: Recognition}

Recognition was a step beyond exposure (i.e., personal experience or direct observation), whereby the CIT not only observed but also realized and identified when social justice issues such as inequity were occurring. In other words, the CIT comprehended injustice, rather than merely observed it. Recognition occurred in many forms, such as awareness of systems, injustice, own privilege, client needs relative to injustice, and potential solutions to systemic problems. Recognition required self-awareness, awareness of others (i.e. empathy; theory of mind), and knowledge of social justice issues.

Pre-program. CITs who were exposed to social injustice before entering the counselor education program were far more likely to possess formalized understandings of injustice, such as privilege, prejudice, discrimination, oppression, and marginalization. One pre-practicum CIT had worked for a transitional housing facility prior to entering the program and had observed how systemic forms of inequality had resulted in dehumanization:

A resident told me, "People are treated like trash, and it's our job to pick them up off the street." On our average day, we do treat people like trash. I think our job as counselors is to recognize those who have not been given that privilege, and to lift them up, to literally pick them up off the streets and say, "You're not trash, you're human.” I think that when people can see their humanity, that's when healing can begin. (Participant E)

In contrast, CITs without personal experiences of social injustices were less likely to be familiar with those terms and few possessed deep and nuanced understandings of inequity pre-program.

Pre-practicum. Pre-practicum CITs reported developing awareness and knowledge of social justice issues through aspects of the curriculum that included coursework, outside of class discussions with faculty, and targeted readings. Most CITs felt prepared to address social justice issues during practicum. However, a few CITs felt unsure about their preparation to recognize and address social justice issues affecting clients as they entered practicum, which appeared to cause some degree of anxiety. One pre-practicum CIT stated:

Yeah...um, part of it, I think, is just, um, being, you know, kind of brand new [laughter]. I'm just kind of generally unsure, and nervous, and still figuring things out...I'm still, um, you know... some of these 
issues we haven't even discussed in class. So, um, that would be the reason why I'm still not comfortable. (Participant S)

While CITs with childhood exposure to social injustice typically possessed an awareness and knowledge of social justice issues, only CITs with prior work experience possessed a knowledge of available resources to help clients. Most CITs developed an awareness of knowledge of available resources through their supervised field experiences.

Supervised field experiences. During field experiences and in supervision, most CITs mentioned recognizing social justice and advocacy issues affecting clients. CITs recognized client injustices even when their clients did not. CITs seemed more capable to identify and define social justice as a concept, which appeared more difficult for some CITs prior to practicum and internship. CITs also recognized more nuanced social justice issues such as client internalization of systemic problems and how social injustices can impact clients differently. CITs also began to "see the big picture" and became aware of broader systemic issues impacting clients such as mental health funding and the influence of the current political climate. As the statement below from a post-internship CIT indicates, CITs began to realize how social justice issues affected the counseling process.

I sat in sessions where the client had to take the bus and it took them an hour to get there. And on top of that they are homeless, can't get their social security, and all these different issues. [deep sigh] It was really hard for me to grasp how someone could still come in to therapy... They have all these different factors against them. (Participant T)

The CIT's site placement appeared to influence their degree of recognition for social justice issues facing their clients. This seemed particularly true for internship experiences, compared to practicum experiences. CITs felt that community mental health sites seemed to focus more on social justice training than others. When social justice issues were a clear focus in the agency, CITs reported feeling comfortable with talking to supervisors about these issues. Some supervisors introduced these topics during supervision, though it appeared most common for supervisees to be responsible for bringing social justice topics to supervision discussions. Most CITs interning in private practice settings noticed through campus-based group supervision that fellow classmates interning in community mental health settings were trained to recognize social justice issues in far more depth, and felt they had missed a training opportunity.

As a result of field experiences, some students recognized gaps in their training program. Students reported needing training in specific advocacy skills during practicum such as "advocating for disability assessment within the school system" and "writing to legislature." Some students reported feeling either unaware or untrained in advocacy skills. These gaps did not appear as pronounced during internship. For example, a post-internship CIT shared:

Well, quite honestly... I don't feel like we actually talked about any real social justice issues in our classes. We didn't talk about health care, we didn't talk about wages, the prison industrial complex, any of the things that we, as a counselor, need to be working on to make people's lives better. It was disappointing to say the least. (Participant J)

In addition, some students wanted their faculty members to provide a clearer explanation for the relevance of social justice training to counselor education.

\section{Stage 3: Action}

CIT recognition of social justice was strongly influenced by exposure through personal experience and direct observation (i.e., self and other). For most CITs, this recognition resulted in action responses that included offering support through listening, sharing of resources, and planning and implementing advocacy action steps 
to address systemic issues causing inequity.

Pre-program and pre-practicum. CITs with prior work experience in the mental health field were the only participants who reported addressing interactional justice prior to practicum, such as providing referrals and resources to clients. One pre-practicum CIT shared:

Every client that I had, I tried to do as much as I possibly could. For instance, I once arranged visitations for a child to see their biological parents. The kid was picked up by a stranger and taken to the meeting. I made sure that the driver was consistent, that the kid had the same driver all the time, and there was not a change. To me, that was advocacy. (Participant B)

No CITs addressed procedural or distributive justice issues (Lewis, 2010) before starting practicum.

Supervised field experiences. During supervised field experiences, all CITs attempted to demonstrate dignity and respect for their clients through providing support in the form of listening to the client, validating their experiences of injustice, and reinforcing resilience. Some CITs intentionally brought up social justice topics in conversation and at times educated clients about social justice issues, whereas other CITs waited for clients to raise the topic. One post-practicum CIT reported that helping the client conceptualize their problems as social injustice was empowering:

The issues that my clients have, a lot of times they don't realize that it is a systemic thing. They just see it as their own personal problem. Once you set that spark, like, "hey, you know, this is really a systemic thing also," it kinda helps people not feel so alone and opens people up to explore how to navigate those certain situations where they are not being set up for success necessarily. (Participant A)

CITs also developed a deeper understanding of how the counselor's role extended beyond the counseling room. Counselors often took on case management duties such as coordinating systems of care, finding and sharing resources with clients, and helping clients navigate supportive housing and legal systems. By the conclusion of the internship experience, many CITs had planned advocacy action steps though few had taken them. Advocacy planning seemed to exist on a continuum from organized and well-formed to tentative and preliminary. CITs faced barriers and "stumbling blocks" that had prevented them from implementing their plans. Most commonly, CITs felt they lacked the time to plan and implement advocacy action steps. CITs reported struggling to manage coursework requirements and demands at their internship site, and felt that graduate school itself was a barrier to advocacy. As a post-internship CIT shared:

I think it's really difficult to advocate. Because at the agency where I'm interning, there's not much down time. There is usually so much paperwork that it's difficult. And I know that right now, being in grad school and working, it makes it even more impossible. There is only so much time. What can you do? Can you write a big paper to your legislature about every single client now? You know, you need to pick and choose. (Participant $\mathrm{S}$ )

CIT knowledge of social justice and self-confidence was also a barrier to advocacy. A few CITs solely equated serving clients from disadvantaged backgrounds with social justice advocacy, and thus equated social justice counseling competence with demonstrations of interactive justice only, without consideration for procedural or distributive justice (cf. Lewis, 2010). Other CITs continued to feel that their advocacy skillset was limited, and lacked confidence to advocate during their internship.

CIT advocacy actions also appeared to be prevented by strong negative emotions. Powerlessness in the face of seemingly immovable systems that supported injustice was the most common negative emotion experienced by CITs. Some CITs experienced helplessness, stating that they were unsure of what to do to address systemic-level injustices. The frequency and severity of exposure to social justice experiences in community mental health agencies felt overwhelming to some CITs, who recognized limitations in "what can be done." One CIT reported avoiding the topic as a coping mechanism. As one post-internship CIT shared, 
Now that I have had almost a year of experience, I feel like I have got, um [pause] almost too much awareness... kinda to the point that it's frustrating. There are so many barriers that are bigger than our work individually. [Sigh] Sometimes, you know that nothing can be done until many years down the road. So, I think it's frustrating in that sense. You feel a little bit powerless. There's things you can do, but there are a lot of things you can't do. (Participant T)

Some CITs did implement advocacy action steps. CITs met with local government officials, K-12 administrators, and school counselors to advocate on behalf of their clients. The focus of these advocacy efforts was a mix of procedural and distributive justice. As one CIT mentioned post-internship: "I have learned in my internship to advocate. Making sure they are not homeless, finding transitional housing, I've done that with my clients. Even sometimes, talking with their school counselors or the teachers, or their PCPs, or social workers" (Participant D). Another post-internship CIT stated,

I've done everything from meeting with legislators to knocking on doors and talking to people in neighborhoods, raising money to lobby. I've been in a meeting with the governor about the impact of medical debt on patients especially with chronic and ongoing illnesses who don't have health insurance. I do think that being able to get my degree has just bolstered my ability to go out into the community and do some more of this work. (Participant J)

CITs seemed to be planning more advocacy action steps as they progressed through their supervised field experiences. During practicum, five CITs had planned advocacy action steps, and only two had taken action. By the conclusion of internship, 10 CITs had planned advocacy action steps, and three had taken them. Thus, it appears that CITs were far more likely to plan advocacy action steps during internship though it still remained uncommon for CITs to carry out those action steps.

\section{Factors Influencing the Developmental Process}

Two factors appeared to influence whether the CIT responded to exposure experiences by recognizing social injustices and acting to address them; self-reflection and attitudes.

Self-reflection. CIT self-reflection appeared to be an integral part of the developmental process. Previous approaches to social justice training have also emphasized the role of self-reflection in developing social justice counseling competencies (e.g., Ratts, Toporek, \& Lewis, 2010). Self-reflection facilitated a recognition of social justice issues and opportunities for advocacy, often prompting action, which in turn created greater exposure. For example, exposure experiences during practicum or internship often resulted in CITs reflecting on their prior experiences and observations, and re-evaluating their own awareness and knowledge. Exposure experiences led some CITs without significant prior exposure to social injustices to become aware of their lack of earlier exposure and to re-examine their privilege, particularly White trainees. These CITs experienced a transformation through self-reflection in response to exposure experiences during practicum and internship. In addition, CITs who had prior exposure to social injustices, particularly during childhood, experiencing an evolution from a personal to professional understanding of social justice. These CITs also seemed to experience self-reflective transformation in response to social injustice exposure during practicum and internship.

Attitudes. The CITs' attitudes toward social justice seemed to pre-exist the training program and appeared to influence whether the CIT was open to new exposure experiences. CITs appeared to possess an intrinsic motivation (Ægisdóttir, \& Gerstein, 2010) toward social justice training. No CITs in the study reported holding negative or dismissive attitudes toward social justice training and practice. CIT openness impacted their recognition of new exposure experiences and whether they were willing to take action. An open stance appeared more likely to result in learning from exposure, whereas a closed stance (which included pre-existing notions that one had "arrived" as a social justice advocate) seemed less likely to result in the CIT learning from the exposure experience. As an example, Participant B was a CIT with an open stance who reported at 
the conclusion of their internship: "I want to become the kind of person that helps the community change." In comparison, Participant E was a CIT with a closed stance who stated that they "came in the program already being really aware of" social justice issues. During both post-practicum and post-internship, this CIT reported that their social justice awareness and knowledge was "from previous experience" (i.e., pre-program) and reported that the social justice aspect of the curriculum had merely "made me enjoy my soapbox." When asked about what they were learning in the counseling program about social justice, this CIT acknowledged: "I don't feel like it did a whole lot to be honest... I don't know how much it really affected me." Perhaps as a result, this CIT reported that "I don't really feel too comfortable with advocacy action steps as a counselor" during supervised field placements and was not bringing up these concerns in supervision.

\section{Discussion}

The purpose of this study was to answer the research question of how, when, why, and to what extent do CMHC trainees develop social justice and advocacy counseling competencies during their master's-level practicum and internship experiences. Through the use of a grounded theory methodology, the authors identified the process (i.e., the "how" and "when" of the research question) by which CITs appeared to develop social justice counseling competencies. CITs appeared to follow a linear yet recursive trajectory of development. The first stage of development, exposure, occurred prior to the counselor education program for some CITs. For others, they reported being first exposed to social justice issues during their program. During field experiences, most students became able to recognize when social injustices were occurring and responded most frequently through demonstrations of support such as listening, validating, reinforcing resilience, and providing case management. By the conclusion of their internships, many CITs had begun to plan advocacy action steps to address procedural and distributive justice (Lewis, 2010), though few carried out these plans. The progression of competency development (exposure, recognition, action) was related to, though different than, existing aspirational models of social justice counseling competency (e.g., AKSA by Ratts et al., 2016; AKS by Sue et al., 1992). For example, recognition preceded action in this study, similar to Ratts et al.'s (2016) progression of awareness and knowledge preceding advocacy. Unlike Ratts et al.'s (2016) model, this study distinctly found that exposure to social justice issues was a key component to competency development and occurred throughout the developmental process.

Several factors seemed to influence this developmental trajectory (i.e., the "why" of the research question). Throughout the process, CITs responded self-reflectively to their exposure, recognition, and action, which seemed to help them progress developmentally and supported their emerging identities as social justice advocates. Prominent authors have previously cited the importance of self-reflection in the development of social justice counseling competence (e.g., Ratts et al., 2010). For some CITs, their motivations and attitudes toward social justice appeared to hinder their development, especially for CITs who entered their counselor education program with pre-existing identities as social justice advocates. For example, the CIT who reported that their social justice training in the program merely "made me enjoy my soapbox" also reported post-internship that they "don't really feel too comfortable with advocacy action steps as a counselor." This finding ran contrary to the results of a prior study by Nilsson and Schmidt (2005) who found that self-identifying as a social justice advocate predicted engagement in social justice advocacy. It was, therefore, unclear as to what effect intrinsic motivation (Ægisdóttir, \& Gerstein, 2010) had on the development of social justice counseling competence in this study. Intrinsic motivation and positive attitudes toward social justice training did not seem to result in enhanced development of social justice counseling competence for all CITs in this study, and actually seemed to hinder development for some CITs.

\section{Research Implications}

The extent to which CITs developed social justice counseling competence varied by participant. CITs in this study were far more likely to develop awareness and knowledge of social justice issues than take action 
to address inequalities. This was consistent with a prior study by Nilsson and Schmidt (2005) who found that advocacy actions were uncommon among CITs. If the CMHC program under study is representative of other CMHC programs, it is likely that even programs with a social justice emphasis tend to focus more on CIT recognition of social justice issues rather than having these individuals take action. CITs in other training programs may thus develop social justice counseling knowledge and skills, without implementing them during field experiences. Further studies could investigate the extent to which counselor education programs require students to not only plan but also execute action steps during master's-level internships. Future studies also could examine CIT skills in advocating for clients, as participants in this study may have felt unprepared to take advocacy actions because of lack of skills in this area.

Furthermore, future studies are needed that examine the interwoven concurrent development of multicultural and social justice competencies. For example, several CITs in this study had limited exposure to social injustices because of their White racial identity and White privilege. Future studies could compare the development of social justice competencies among CITs with varying cultural identities, including racial identity.

\section{Implications for Counselor Education Programs: Addressing Barriers to Client Advocacy}

The findings of this study could be useful for other counselor education programs who are required by the CACREP (2016) standards to implement social justice training within master's-level programs. In this study, CITs appreciated an intentional attempt to integrate social justice training into the curriculum prior to field experiences. Despite this appreciation, CITs appeared to want even more social justice training earlier in the curriculum. The counselor education program in this study could have integrated even more social justice training experiences during the first year of studies pre-practicum. As an example, CITs in this study developed knowledge of available resources through their supervised field experiences, and may have benefitted from earlier training in case management resources pertinent to social justice issues. Service learning experiences may be one useful tool for initiating social justice training earlier in the program (Bemak et al., 2011).

During practicum and internship, CITs seemed to benefit from self-reflection activities, consistent with prior literature on the development of social justice counseling competence (Ratts et al., 2010). CITs could be prepared to identify and reflect on exposure experiences that occur on site through structured exercises such as journals and class discussions. Counselor education programs also could encourage CITs to identify systemic barriers that are experienced by the people they serve, and plan advocacy action steps to address procedural or distributive injustice. Requiring CITs to take advocacy action steps during supervised field experiences in counselor education programs should be paired with support. CITs reported lacking time to advocate because of their site's demands on their time, and also because of the rigors of graduate school during field experiences. A prior study of doctoral-level psychology trainees reported that creating time and space for social justice training was essential to the development of trainee competency (Singh et al., 2010).

The CIT's practicum and internship field placement site also seemed to have an impact on their development of social justice counseling competence. Participants in this study reported that some sites provided better social justice training than others. Counselor education programs could consider screening sites more carefully to ensure that students are adequately trained to recognize and address social justice issues. Counselor education programs also could consider conducting a needs assessment of their site supervisors' interests related to social justice training. Counselor education programs could then provide training as needed (Lewis, 2010).

\section{Limitations}

This study had several limitations. Because this was a qualitative study, findings may not be replicable and also may not be transferable to other counselor education programs who seek to train their CMHC students in social justice counseling competencies. Additionally, more research is needed to explore whether CITs in areas of other specialized study (e.g., school counseling) experience similar or different developmental trajectories for 
developing multicultural and social justice counseling competence. As is common to qualitative interviews, the source of data was solely self-report which could have impacted the validity of findings. We frequently observed as a coding team that interviewees did not provide examples in support of their claims. It is, therefore, possible that the data may be inaccurate.

The authors chose to transcribe interviews 12 months after the study had been completed to ensure that trained graduate students who transcribed interviews had no connection nor exposure to participants in the study. All transcriptionists entered the counselor education program after all participants had graduated from the program. Because the authors analyzed the data after the study had been completed, the authors took the risk of the interview questions not adequately addressing the research questions. If this had occurred, data may have reached saturation too quickly and codes would have only been sorted into existing rather than new categories, resulting in a reduced amount of categories and themes (Corbin \& Strauss, 2014). Saturation was reached after coding data for nearly all participants (37 of 41). Data saturation after 37 participants did not seem overly premature, because the sample size of this study $(N=41)$ exceeded most guidelines for grounded theory research. For example, Creswell and Poth (2017) had previously suggested 20-30 interviewees was adequate. Data saturation could, therefore, be expected after approximately 20-30 participants. The authors piloted the interview protocol prior to the study to reduce this threat to data trustworthiness and validity. The interview questions adequately collected data to answer the research questions during the pilot study.

Consistent with national trends (e.g., CACREP, 2016, pp. 8-9), White females were overrepresented in the sample. It is possible that different themes would have been observed in a more diverse sample. Furthermore, the study was conducted in a region of the country which is known to be fairly progressive in its political leanings. The themes that emerged from this study, therefore, may not be transferable to counselor education programs in other regions of the country with less progressive leanings. For example, no CITs in this study held negative attitudes toward social justice training or practice, which may not be representative of CITs in other counseling programs. Future studies could be conducted, therefore, with CITs from different geographical regions, with CITs in different specialization tracks (e.g., school counseling), and with a sample that represents greater racial/ethnic identity. Finally, the sample had a wide age range (22 to 56), with an average age of 31.8 years. This age range may not be consistent with other counseling programs who have either a predominantly younger student body (i.e., mostly students who have just completed undergraduate education) or who serve older adult learners.

CIT responses also may have been biased somewhat by the positioning of the interviewers. The interviewers had emic positioning as alumni of the program and had contact with the first author. While CITs had no prior or subsequent exposure to interviewers, some participants may have felt that they needed to report higher degrees of competence to please the interviewer because of their potential connection to faculty. An interviewer with etic positioning may have elicited more guarded responses, though they also may have encountered social desirability response bias to a lesser extent. Despite clear instructions in the informed consent about the participant's right to withdraw from the study at any time, and CITs being informed that data would not be analyzed until after their graduation from the program, it was possible that some CITs believed they could not withdraw from the study because of their status as current students in the program. This may partially explain the high retention rate of students. Other possible reasons for high retention include participants enjoying their participation in the study, and having a value towards social justice training and wanting to advocate for more social justice training in the program's curriculum.

\section{Conclusion}

This study was the first to identify the process by which CMHC CITs develop social justice counseling competencies. Further studies are needed into the experiences of CITs in other counselor education programs to compare and contrast the experiences of CITs from this study, and to gauge the transferability of the grounded theory developed in this article. Greater geographic representation and racial/ethnic diversity in the 
CIT sample are important considerations for subsequent research studies that seek to evaluate the replicability and transferability of the findings. Future articles also could address the effectiveness of strategies that attempt to remove CIT barriers to client advocacy. Finally, quantitative studies also could be useful to measure the outcome of social justice training programs on CIT development of social justice counseling competencies.

\section{Corresponding Author}

Correspendence concerning this article should be addressed to Thomas A. Field, Boston University School of Medicine, 72 E Concord St, Suite B212, Boston, MA 02118. Email: tfield@bu.edu 


\section{References}

Bemak, F., Chung, R. C.-Y., Talleyrand, R. M., Jones, H., \& Daquin, J. (2011). Implementing multicultural social justice strategies in counselor education training programs. Journal for Social Action in Counseling and Psychology, 3(1), 29-43. Retrieved from http://www.psysr.org/jsacp/bemakv3n1-11_29-43.pdf

Charmaz, K. (2014). Constructing grounded theory (2nd ed.). Thousand Oaks, CA: Sage.

Collins, S., Arthur, N., Brown, C., \& Kennedy, B. (2015). Student perspectives: Graduate education facilitation of multicultural counseling and social justice competency. Training and Education in Professional Psychology, 9, 153-160. doi:10.1037/tep0000070

Colquitt, J. A., \& Greenberg, J. (2003). Organization justice: A fair assessment of the state of the literature. In J. Greenberg (Ed.), Organizational behavior: The state of the science (pp. 165-210). Mahwah, NJ: Erlbaum.

Corbin, J., \& Strauss, A. (2014). Basics of qualitative research: Techniques and procedures for developing grounded theory (4th ed.). Thousand Oaks, CA: Sage Publications, Inc.

Council for the Accreditation of Counseling and Related Educational Programs. (2016). 2016 CACREP Standards. Retrieved from http://www.cacrep.org/wp-content/uploads/2017/08/2016-Standards-withcitations.pdf

Council for the Accreditation of Counseling and Related Educational Programs. (2016). Annual report 2016. Retrieved from https://www.cacrep.org/about-cacrep/publications/cacrep-annual-reports/

Hegtvedt, K. A. (2007). Theories of social justice. In G. Ritzer (Ed.), Blackwell encyclopedia of sociology. Retrieved from http://www.blackwellreference.com/

Hipolito-Delgado, C. P., Cook, J. M., Avrus, E. M., \& Bonham, E. J. (2011). Developing counseling students' multicultural competence through the multicultural action project. Counselor Education and Supervision, 50, 402-421. doi:10.1002/j.1556-6978.2011.tb01924.x

Kottler, J. A., Englar-Carlson, M., \& Carlson, J. (2013). Beyond the 50-minute hour: Therapists involved in meaningful social action. New York, NY: Routledge.

Lewis, B. L. (2010). Social justice in practicum training: Competencies and developmental implications. Training and Education in Professional Psychology, 4, 145-152. doi:10.1037/a0017383

Lincoln, Y. S., \& Guba, E. G. (2013). The constructivist credo. New York, NY: Routledge.

Merriam, S. B., \& Tisdell, E. J. (2017). Qualitative research: A guide to design and implementation (4th ed.). San Franscisco, CA: Jossey-Bass.

Mills, J., Bonner, A., \& Francis, K. (2006). The development of constructivist grounded theory. International Journal of Qualitative Methods, 5(1), 1-10. doi: 10.1177/160940690600500103

Patton, M. Q. (2014). Qualitative research and evaluation methods: Integrating theory and practice (4th ed.). Newbury Park, CA: Sage.

Prosek, E. A., \& Michel, R. E. (2016). Transformative learning for counselor trainees: Implementation of the multicultural immersion experience model. International Journal for the Advancement of Counselling, 38(1), 61-76. doi:10.1007/s10447-015-9256-1

Nilsson, J. E., \& Schmidt, C. K. (2005). Social justice advocacy among graduate students in counseling: An initial exploration. Journal of College Student Development, 46(3), 267-279. doi:10.1353/csd.2005.0030 
Ratts, M. J. (2011). Multiculturalism and social justice: Two sides of the same coin. Journal of Multicultural Counseling and Development, 39, 24-37. doi:10.1002/j.2161-1912.2011.tb00137.x

Ratts, M. J., Singh, A. A., Nassar-MacMillan, S., Butler, S. K., \& McCullough, J. R. (2016). Multicultural and social justice counseling competencies: Guidelines for the profession. Journal of Multicultural Counseling and Development, 44, 28-48. doi: 10.1002/jmcd.12035

Ratts, M. J., Toporek, R. L., \& Lewis, J. A. (Eds). (2010). ACA advocacy competencies: A social justice framework for counselors. Alexandria, VA: American Counseling Association.

Singh, A. A., Hofsess, C. D., Boyer, E. M., Kwong, A., Lau, A. S. M., McLain, M., \& Haggins, K. L. (2010). Social justice and counseling psychology: Listening to the voices of doctoral trainees. The Counseling Psychologist, 38, 766-795. doi: 10.1177/0011000010362559

Sue, D. W., Arredondo, P., \& McDavis, R. J. (1992). Multicultural counseling competencies and standards: A call to the profession. Journal of Multicultural Counseling and Development, 20, 64-88. doi:10.1002/j.2161-1912.1992.tb00563.x

Sue, D. W., \& Sue, D. (2013). Counseling the culturally diverse: Theory \& practice (6th ed.). New York, NY: John Wiley.

Ægisdóttir, S., \& Gerstein, L.H. (2010). International counseling competencies: A new frontier in multicultural training. In J. G. Ponterotto, J. M. Casas, L. A. Suzuki, \& C. M. Alexander (Eds.), Handbook of Multicultural Counseling (3rd Edition) (pp. 175-188). Thousand Oaks, CA: Sage Publications. 


\section{Appendix A: Interview Questions}

1. Please share how you self-identify regarding the following descriptors: Gender identity, sexual or affective identity, race and ethnicity, age, and years of experience in the mental health field before entering the counselor education program.

2. To what extent have you seen or currently see how social justice or advocacy issues impact your own life or your environment?

3. To what extent do you understand broad social justice issues such as "prejudice," "oppression," and "discrimination," and how often do you see how these issues impact your clients?

4. To what extent do you feel prepared to discuss any and all social justice issues with your clients?

5. To what extent have you taken advocacy action steps?

6. How did your experience with a social justice counseling during practicum or internship influence your own identity as a counselor, if at all?

7. Last question: What else could I have asked you about, that I did not think to ask? 